\section{The moralistic fallacy}

Bernard B. Davis of the Bacterial Physiology Unit, Harvard Medical School, discusses whether or not scientific inquiry should be blocked on moral grounds

THE increased focus of our age on social justice, and on the need to control the costs of technology, has had admirable consequences. But it has also reactivated an old threat to science: the demand that certain kinds of scientific knowledge be forbidden. George Steiner, in his recent Bronowski Memorial Lecture, rejected this proposal, on the pragmatic grounds that it just won't work. However, Nature's editorial of 2 February, drew a different conclusion: that we are now groping for a code to protect society from dangerous knowledge, much as we have developed ethical codes to protect the subjects of biomedical research.

Since this issue is of central importance for the future of science we must consider the arguments very carefully. I wish to discuss some that did not appear in Steiner's lecture or in Nature's editorial. I shall focus on the heritability of intelligence, which Steiner views as the most intractable among the several kinds of dangerous scientific knowledge.

First, the analogy to medical research proposed in the editorial, though plausible at first glance, in fact ignores a crucial distinction: between actions that are themselves dangerous and knowledge that might lead to dangerous actions. Medical investigators do indeed accept ethical limitations on dangerous procedures, that is, those that would expose an experimental subject to loss of dignity, pain, or risk. And investigators in behavioural genetics are subject to analogous limitations: they cannot mate humans at will, or transfer identical twins into different homes, even though these procedures would be powerful tools for advancing knowledge. On the other hand, medical investigators are not forbidden to seek knowledge simply because it may be painful, in its prognostic implications, for the subject or for others. So medicine does not provide a model for justifying limitations on the knowledge sought in other areas.

The very concept of dangerous knowledge is also shaky. Ever since the discovery of fire, and of cutting tools, it has been clear that virtually any scientific knowledge can be used for good or for ill: the costs and benefits depend entirely on how it is used. Moreover, we have only a very limited ability to foresee the eventual scientific benefits of a new discovery: science is a continuous web, and fundamental advances often arise through unexpected crossfertilisation. For example, there are very good reasons to forbid human cloning: but if we should forbid any research in cell biology that might bring cloning nearer we would seriously impair advances in cancer research. We must therefore ask whether it is more rational to try to protect society by limiting the areas open to fundamental inquiry, or by focusing on earlier assessment and improved control of new technological applications of scientific knowledge.

We must also consider the rather ahistoric and absolutist conception of justice implied in the suggestion of a fundamental incompatibility between man's hopes of justice and decency and certain catcgories of truth. For though it is clear that the concept of justice has certain stable features, it is also clear that the rules of behaviour in any society, and the assumption underlying these rules, are continually evolving especially when the society is faced with new knowledge and new technologies. For example, we have weathered the storm created by Darwin; and though the supernatural basis for a moral consensus was shattered by his elimination of special creation, we have meanwhile developed a radical increase in our sensitivity to problems of human rights. Can we not trust posterity also to adapt its notions of morality to further new knowledge?

More specifically, there seems to be a pervasive fear of the social impact of genetics, arising largely from the pseudoscientific extrapolations of social Darwinism and Nazi racism. I would suggest that this view does not reflect the real contributions of this field. In fact, one of the historical grounds for racism was the pre-scientific conception of races as permanent, distinct products of creation. But evolution made us aware of the brotherhood of all races. Another rationale for racism was the typological conception of the nature of race- a view based on the Platonic characterisation of groups in terms of an ideal "type", subject to only minor deviations in concrete individuals. But this misconception was destroyed by population genetics, which demonstrated the great genetic heterogeneity of all races, the statistical nature of the differences between them, and the extensive overlap of these distributions for most traits. This field has thus contributed far more than is recognised to public awareness that one cannot determine an individual's capacities by identifying him with an ethnic group.

Finally, we must ask how much the current reasons for proscribing an area of knowledge really differ from those used by Urban VIII, Bishop Wilberforce, or Lysenko. The main difference is that science is penetrating increasingly into areas that generate moral problems, and that generate technological capacities for great destruction. Since Steiner considered the former the more intractable, we might look more closely at his suggestion that a demonstration of heritable differences in the distribution of abilities among different ethnic groups might be irreconcilable with human justice. Apart from the implication of a fixed rather than an adaptive concept of justice, noted above, this proposition seems to be blaming the messenger for the message. For science does not create the realities of nature: it only discovers them. And if it is not allowed to discover them they will still be there, determining whether or not our assumptions and our predictions turn out to be correct.

Recognition of the distinction between reality and the knowledge of reality has profound consequences. It tells us that if we wish to build social policy soundly we must not confuse the normative with the empirical. More specifically, we must rest the goal of racial justice on grounds of moral conviction, rather than on vulnerable assumptions about questions of fact; and we must recognise that we can adapt our social institutions to our evolutionary legacy, but not vice versa. We must also recognise that justice and equality are subtle and complex concepts however simplistic the forms that they assume in the ideological marketplace: and these concepts will eventually have to be defined in ways that do not depend on a particular assumed distribution of abilities. If we choose otherwise, and suppress human behavioural genetics for fear that the results may contradict our assumptions, the costs may be high. For a major goal of this field, long emphasised by J. B. S. Haldane, is to help us to adjust educational procedures to individual differences in cognitive potentials and in patterns of learning.

For several reasons, then, the assumption of an inherent conflict between genetics (or other areas of science) and iustice seems philosophically unsound. The objections can be summarised quite simply: since blocking off an area of inquiry on moral grounds fixes our knowledge in that area, it becomes. in effect, an illogical effort to derive an 'is' from an 'ought'. I would suggest that we call this procedure the moralistic fallacy, since it is the mirror image of what Hume and G. E. Moore identified as the naturalistic fallacy. But, alas, identification may not get us very far. For as Stephen Toulmin recently emphasised in Daedalus, we are in the midst of one of history's swings between a romantic concern with the good and a classic concern with truth. $L$ 